\title{
BUILDING ARCHAEOLOGY DOCUMENTATION AND ANALYSIS THROUGH OPEN SOURCE HBIM SOLUTIONS VIA NURBS MODELLING
}

\author{
F. Diara ${ }^{\text {a }}$, F. Rinaudo ${ }^{\text {a }}$ \\ a DAD, Department of Architecture and Design, Politecnico di Torino, Viale Mattioli 39, 10129 Torino, Italy \\ filippo.diara@polito.it, fulvio.rinaudo@polito.it
}

KEY WORDS: Building Archaeology, Documentation, HBIM, NURBS, Open source, Scan-to-BIM

\begin{abstract}
:
The implementation of historical information within BIM (Building Information Modelling) platforms has experienced great development processes during last years, generating excellent studies based on Historic Building Information Modelling (Murphy et al., 2009; 2013). The HBIM developing growth is certainly explained due to advantages concerning the documentation step as well as monitoring operations for Cultural Heritage assets. In this sense, information concerning historical architectures can be extracted directly from walls and masonries and it is related to stratigraphic information derived from archaeological analysis: this kind of analysis is fundamental in order to comprehend the evolution of the construction site through the identification of layers due to modifications and actions (Parenti R., 2000).

The inclusion of stratigraphic analysis inside a HBIM workflow could be an innovative point as far as the management and monitoring is concerned. This kind of documentation, that was not designed to be included inside a common BIM platform, could be collected coupled with digital metric information derived from metric surveys even if it is still considered an ongoing research field, especially since Cultural Heritage assets have no BIM standard classification. For this reason, the main goal of this research is to adapt the possibilities of open source solutions concerning BIM methodologies to building archaeology documentation and analysis exploring unconventional strategies and also overcoming 3D modelling limitations of BIM software with free form modeler based on NURBS algorithm (Oreni et al., 2014), developing a particular scan-to-BIM process that, owing to the used opens source solutions and algorithm, can be renamed scan-to-openBIM via NURBS.
\end{abstract}

\section{INTRODUCTION}

The creation of a HBIM (Historic Building Information Modelling) platform for Cultural Heritage assets, such as for restoration and archaeological purposes, involves a deep critic knowledge of the analysed context in order to guarantee a complete documentation and monitoring processes over the time. Then, information plays a key role regarding BIM workflows and may be of different types depending on research needs. In this sense, information concerning historical buildings could be different, from land concessions to written archives, from historical pictures or paintings to past restorations and human memories.

Although it is considered a stable research field in Geomatics, the application of BIM methodologies to building archaeological documentation and analysis as well as Cultural Heritage in general is a novel and pending study that could avoid data fragmentation derived from traditional studies, establishing a watershed between this new court of documentation through BIM methodologies and traditional building archaeology analysis, in several cases characterized by paper-based works that are mostly disconnected from the metric and architectural context and from other digital studies (Diara et al., 2018; Beltramo et al., 2019; Bruno et al., 2019)

However, the integration of information not directly designed to be included inside a BIM platform is still a vivid problem as well as a great academic challenge, especially since it depends also on testing experimental and unconventional ways to integrate this kind of historical data on BIM platforms (Murphy et al., 2013; Barazzetti L., 2016; Beltramo et al., 2019; Pocobelli et al., 2019). For these reasons this project has been affected by three questions and purposes that establish in the same time the objectives of this project: 1) Is it possible to create a custom HBIM for Building
Archaeology purposes? 2) Is it possible to create a custom HBIM starting from NURBS modelling? 3) Is it possible to create a custom HBIM by using open source solutions?

All these questions and purposes can be identified as the willingness to solve different research issues, such as data fragmentation of traditional studies, limitations concerning BIM software modelling tools as well as the possibility of customizing BIM platform (especially looking at IFC classification) depending on specific needs.

\subsection{Methodology}

Focusing on an existing building, this project is based on scanto-BIM methodology, which starts from metric acquisition of the case study, continues with point clouds management and segmentation and then entities classification inside the BIM platform. However, this work is based on a particular scan-to$B I M$ workflow, for the first time renamed scan-to-openBIM via $N U R B S$, that has the same basis of the previous method but principally relies on NURBS modelling (overcoming BIM modelling limitations) and relies on a customized open source BIM platform as FreeCAD, allowing ad-hoc modification for specific researches (Logothetis et al., 2017; Diara et al., 2018). Moreover, this project is also focusing on a non-conventional integration between open source HBIM solutions and building archaeology documentation and analysis (based on stratigraphic archaeological method) and this integration and workflow should not be considered as a proposal and evaluative early research (Diara et al., 2018; Beltramo et al., 2019; Trizio et al., 2019) but as a settled study based on an experimental custom-made workflow applied to the historical and stratigraphic study of the refectory inside the Staffarda abbey (CN, Italy), that required an updated and precise analysis on masonry stratification (Fig.3). 


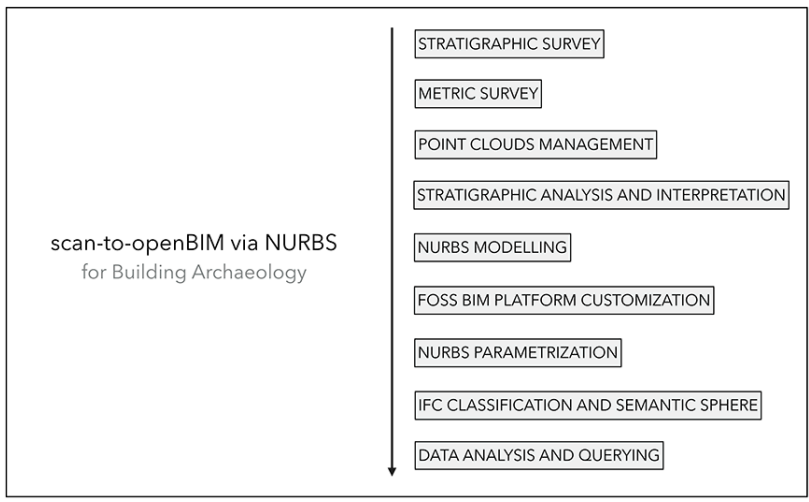

Figure 1. Scan-to-openBIM via NURBS main workflow

\section{STRATIGRAPHY AND ITS ANALYSIS}

Stratigraphy and stratifications have been originally referred to geologic and archaeologic layers, even if the notion of stratifications also regard other situations, such as historical architectures, cities as well as landscapes. Then, stratifications are referred to specific actions: deposits or accumulation actions, erosion or destruction actions, movement or transportation actions. Modifications are therefore caused due to natural / artificial and / or voluntary / involuntary actions affecting also the original conformation of buildings, and this court of analyses generated a particular discipline called Building Archaeology (Doglioni F., 1988; Parenti R., 2000; Brogiolo et al., 2012) because the archaeological documentation and analysis method can be applied to historical architectures where the stratification is evident (mostly medieval architecture) (Fig.2).

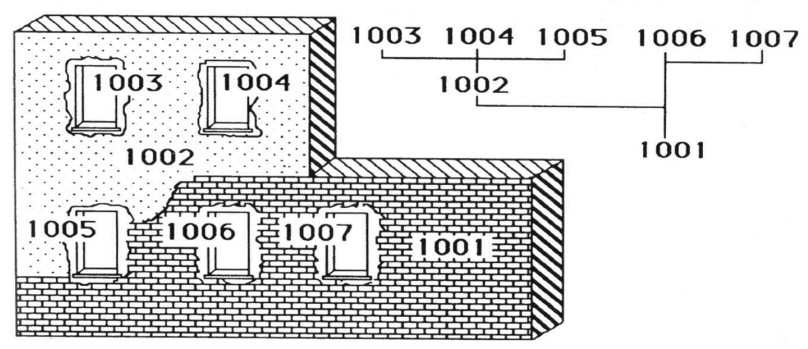

Figure 2. Example of Building Archaeology analysis: notdirectly equality typological relations on Harris' Matrix. (Brogiolo G.P., 2012).

\subsection{Stratigraphic analysis}

Depending on archaeological or architectural contexts, the complexity of stratigraphy requires particular ways of acting and analyses based on documentation and interpretation of stratigraphic units.

Documenting stratigraphy means collecting alphanumerical and graphical data concerning stratigraphic layers, surfaces and evidence (Fig.2). This data is related to photographic, graphical (drawings) and textual (paper-based datasheets) description of stratigraphic units. However, the principal documentation phase is mostly executed by using CAD software for the boundaries' delimitation of units on orthoimages.

The chronological interpretation of the stratigraphy is essentially based on Harris' Matrix (Harris E.C., 2002), that is a schematic relational diagram for graphical representation of physical relations among units; then, through this method the stratigraphic sequence can be detect in order to identify the relative chronology (early interpretation just based on physical relations) and the absolute chronology (initial chronology crossed checked with other external resources) (Parenti R., 2000; Brogiolo et al., 2012).

\subsection{HBIM and stratigraphic analysis}

Since stratigraphic data is an exclusive historical information that cannot be find outward from the context, it become fundamental also for historical buildings studies and for this reason it also become a particular feature to be included inside a HBIM project for building archaeology purposes, because it enables to understand transformations and evolutions of the architectural stratification (constructive and destructive actions on wall surfaces) and then allowing to comprehend mechanical behaviours affecting the static asset (Diara et al, 2018; Beltramo et al., 2019). In this sense, the inclusion of stratigraphic analysis - and then the surface peculiarities of historical architectures (also including weathering processes) - as main historical information inside a HBIM platform could become essential for management and monitoring processes (Diara et al., 2018; Bruno et al., 2019; Beltramo et al., 2019; Pocobelli et al., 2019; Trizio et al., 2019).

\section{KNOWLEDGE PROCESSES}

As mentioned before, the refectory of Staffarda abbey (CN, Italy) has been the case study of this HBIM project. Despite several studies on Staffarda abbey (Beltramo S., 2010; 2016), the architectural complex, as well as the refectory, require constant stratigraphic analyses especially since its structures have experienced different morphological and structural changes during the years. So, it required updated stratigraphic analyses whereby can be understand several modifications occurred to the original morphology of architectural elements visible on wall stratigraphy (Fig.3), especially the vaulted ceiling.

For this reason, the refectory has been surveyed by performing two different knowledge processes, metric survey and stratigraphic survey: a LiDAR metric survey for the purpose of acquiring metric and accurate and explorative and cognitive stratigraphic survey in order to collect sensitive information such as stratigraphy for the comprehension of the historical evolution of the refectory through the stratigraphic analysis.

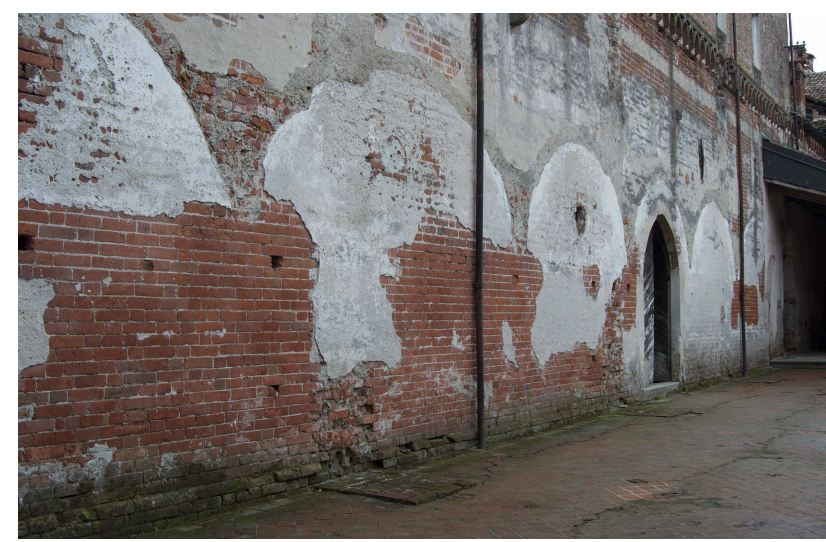

Figure 3. Particular of the refectory entrance (south side of the abbey' cloister)

\subsection{Metric survey and data processing}

LiDAR acquisitions were planned for the purpose of scanning the entire refectory, external fronts as well as the internal area. In total were performed twelve scans, of which three of them were executed for each external front, so in total six external scans. Metric acquisitions produced high density point clouds data that that needs to be managed in order to extract the needed information derived from the metric survey (Macher et al., 2017) for the next NURBS and parametric modelling step for HBIM platform (Fig.4). 


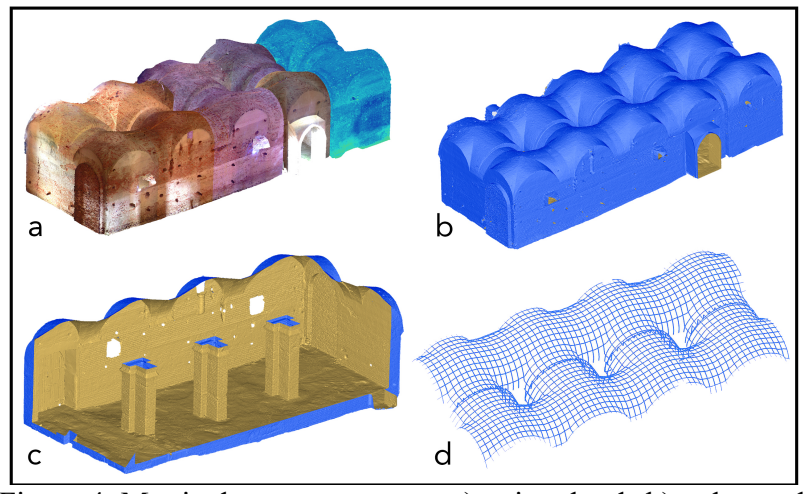

Figure 4. Metric data management: a) point clouds b) polygonal mesh c) internal detail d) planar sections of vaulted system

First of all, triangulated meshes have been generated for the purpose of obtaining a complete reality-based model as well as in order to extract planar sections on which NURBS modelling has been carried out: in fact, profiles generated from planar sections represent a correct framework where hang NURBS curves and surfaces up. Manual segmentation and planar sections extraction phase, despite have proved to be a time-consuming operation, it has been revealed as an important interpretation step of refectory geometries and peculiarities (Fig.4).

At the same time, best fitting planes have been generated for the purpose of overcoming irregularities of the internal clay ground of the refectory, obtaining simplified flat surface that will be managed on Rhinoceros and subsequently as a parametric object inside the HBIM platform.

\subsection{Stratigraphic survey and analysis}

The stratigraphic survey of the Staffarda refectory has been planned for the purpose of documenting and registering stratigraphic units of external (cloister side) and internal fronts: this survey has been coupled to the required photographic and metric acquisition, in order generate rectified images (orthophotos) of architectural fronts to use them as a basis for a detailed map of units and their edges drawn on CAD.

Then, stratigraphic analysis of the refectory has been performed detecting and classifying units by using identification numbers and acronyms such as architectural element (EA), masonry stratigraphic units (USM) and render stratigraphic units (USR). Moreover, internal pillars and groined vaults have been subdivided and catalogued because they are strictly linked to the internal wall stratigraphy (Fig.5).

The interpretation step has been carried out by using Harris' Matrix, or stratigraphic diagram, in order to establish physical relations among units through connection lines. This interpretation has been refined and crossed with precise external historical information, such as historical drawings of the refectory as well as a typological chronology of architectural elements (Fig.5).

Finally, seven chronological periods have been detected, from about 1160 to 1925 , from the early construction site of the refectory (related to a block of suspended round arches) to the principal construction period of 1180-1220 (main brick masonry, openings and architectural elements related to the first ceiling, probably composed by a wooden trussed roof supported by diaphragm stone arches). Main changes are referred to events after the Staffarda Battle in 1690 (characterized by the attacks on behalf of the French armies), especially concerning the removal of external buttresses and gallery in favour of construction site of the first floor and the new vaulted system with the related Tshape pillars replacing the old ceiling (Beltramo S., 2010; 2016).

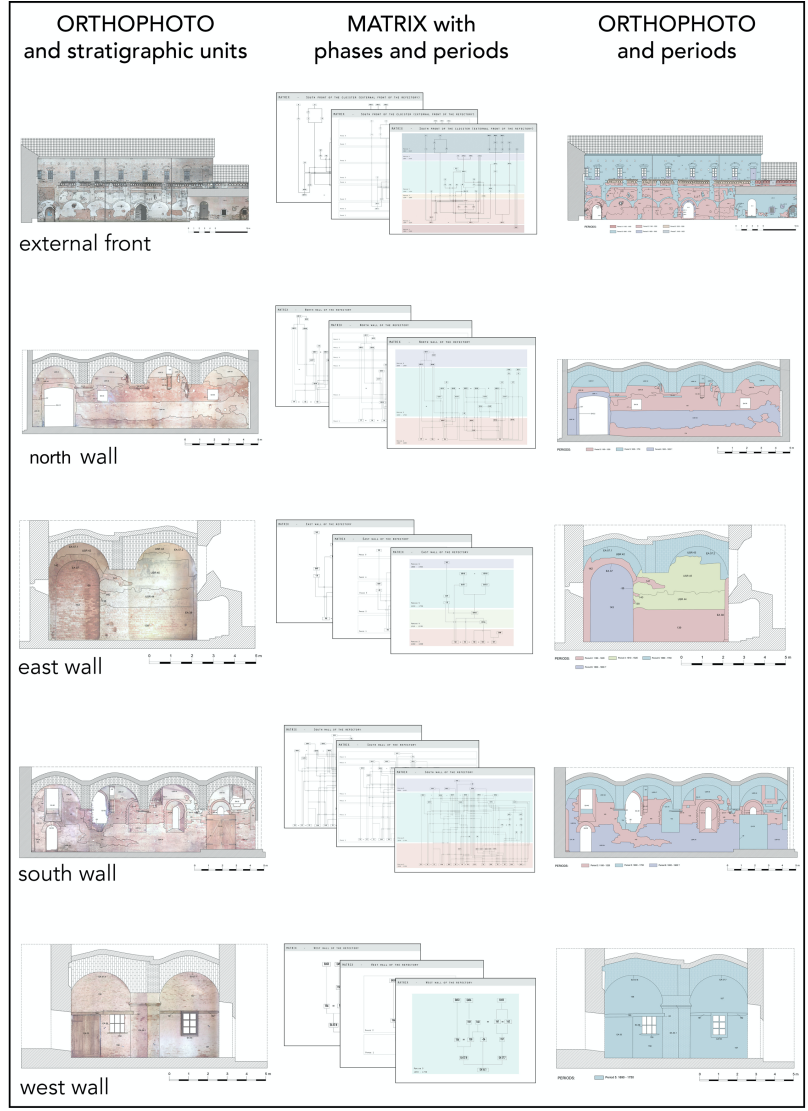

Figure 5. From stratigraphic documentation to analysis and chronological interpretation

\section{NURBS 3D MODELLING}

The 3D modelling of the Staffarda refectory has been performed by using Rhinoceros software and NURBS (Non-Uniform Rational Basis-Splines) curves and surfaces for the purpose of reaching a good level of detail concerning complexes geometries and features of the building.

This decision has been taken especially since actual BIM platforms, including open source solutions as FreeCAD, are affected by modelling limitations, based essentially on predefined libraries of theoretical architectural elements as well as the simplified parametric modelling starting from geometric primitives composing main volumes of architectural elements. So, this modelling choice can be adapted for the refectory as well as Cultural Heritage assets purposes, because their features and peculiarities can be hardly represented by using predefined libraries (Adami et al., 2017; Diara et al., 2019; Giannattasio et al., 2019).

However, NURBS surfaces and objects aren't parametric models and for this reason they cannot be directly implemented inside a BIM platform, but, as we will see, there are different solutions for the purpose of parametrize NURBS models (Oreni et al., 2014; Diara et al., 2019), allowing to modify construction parameters of 3D objects, according to BIM modelling purposes.

\subsection{Modelling the refectory}

Then, NURBS modelling of the refectory started from the imported planar sections and best fitting planes (on Rhinoceros) in order to interpolate NURBS curves and surfaces directly on sections and planes (Fig.6).

The first step was the comprehension of geometric primitives of architectural elements of the refectory, and this procedure has 
been performed manually interpreting geometrical shapes from imported planar sections, formerly subsampled into clean sections concerning individual architectural components of the building. NURBS curves has been therefore interpolated and drawn on sections in order to obtain a simplified wired profile of geometries: acting in this way the whole wired profile of the refectory has been created.

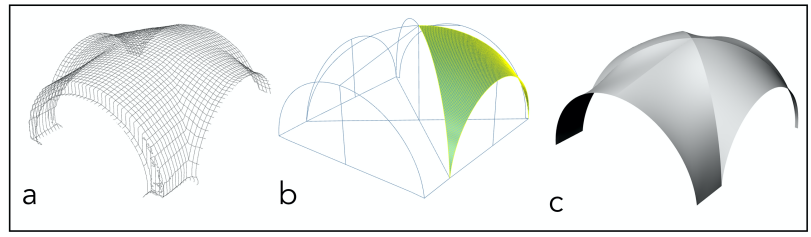

Figure 6. NURBS modelling strategy: from planar sections (a) to simplified wired profile on which surfaces have been modelled (b) to final model (c).

After the comprehension of geometric primitives by creating wired profiles, the modelling of architectural elements has been performed by using and merging principally main surfaces tool inside Rhinoceros: extrusion as solid, loft, sweep and patch. In this regard, internal subdivisions of surfaces (density of curves inside the surface) have been set depending on architectural components complexity, by editing $\mathrm{U}$ and $\mathrm{V}$ subdivision from 30 to 90 . In this way the refectory has been modelled, including the ground, pillars, walls, openings (doors, single-lancet windows, squared windows), anchors, arches, beams, buttresses, columns, stairs and the vaulted ceiling (Fig.7).

Moreover, the refectory model has been classified by using Grade Of Generation (GOG) classification system introduced by Banfi F. (Banfi F., 2016; 2017). GOG, based on 10 points list, evaluates the adopted 3D modelling tools depending also on restitution details: from the simple extrusion (GOG1) to the interpolation of curves and surfaces on a wired profile (GOG9) and on points clouds (GOG10) (Banfi F., 2017). Following this classification, the refectory modelling can be classified by using GOG8 (usage of loft and sweep tools) and GOG9, reaching a high level of detail.

However, the modelling phase has been affected by a voluntary simplification of some geometrical shapes and architectural elements, and this way of acting has been chosen for the next parametric modelling phase inside FreeCAD, in order to ease the creation of the HBIM conceptual model, and not another realitybased model. Indeed, despite the obtained model of the refectory has a high density of surfaces, shapes as well as details, it hasn't the thickness parameter due to the presence of NURBS surfaces, so it cannot be integrated inside the FreeCAD BIM platform without performing the required parametrization processes.

\subsection{Stratigraphic units modelling}

Stratigraphic units have been mapped and individually modelled on the entire NURBS model of the refectory (Fig.7). This operation started by importing orthophotos on Rhinoceros depending on walls as well as on right coordinates systems and it has continued by drawing stratigraphic units' edges on orthophotos by using NURBS poly-curves, obtaining a wired profile for each unit. Moreover, the units' surface has been generated thanks to Patch tool, by editing $\mathrm{U}$ and $\mathrm{V}$ internal subdivisions of curves from 30 to 60 .

\section{FREECAD FOSS HBIM PLATFORM}

The willingness to test and observe how a BIM solution can adapt its workflow to Cultural Heritage assets brings this project towards new possibilities resulted from FOSS (free and open source) solutions, trying to understand how open BIM software is convenient for the purpose of creating a full operative HBIM platform for buildings archaeology purposes (Logothetis et al., 2017; Diara et al., 2018; Beltramo et a., 2019; Diara et al., 2019). In this sense, FreeCAD software has been used and fully exploited for this project.

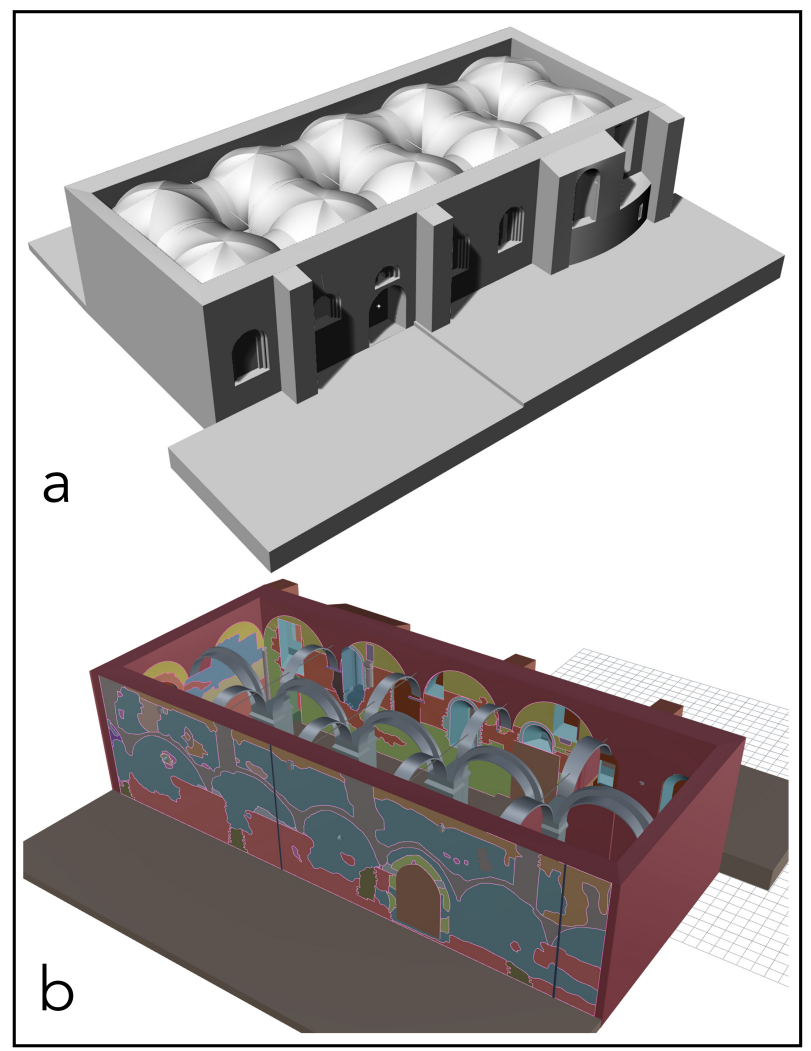

Figure 7. Refectory NURBS model (a) also including all stratigraphic units (b)

\subsection{Compiling and modifying FreeCAD}

FreeCAD is a FOSS CAD and BIM software (developed by using Python and $\mathrm{C}++$ ) based essentially on dynamic parametric modelling. However, as other FOSS software, FreeCAD needs to be compiled and integrated with necessary libraries and additional features, making it its potential. Indeed, through the big community behind, FreeCAD grows and improves its functionalities and stability, allowing new applications and possibilities.

In this sense, FreeCAD has been customized on different levels, especially in three areas: 1) libraries, macros and workbenches; 2) material database; 3 ) roles and IFC entities classification.

5.1.1 Libraries, macros and workbenches: Regarding the first group, a library as IfcOpenShell is fundamental for BIM purposes, in fact IfcOpenShell is an open source library that allows managing, importing and exporting the IFC format (Industry Foundation Classes), a necessary requirement for the BIM platform, developed by buildingSMART and widely adopted in the AEC industry and BIM applications, regularised by the International Organization for Standardization (ISO).

Different additional workbenches have proved to be fundamental for this project and in general for HBIM purposes: in this regard, BIM workbench has been included because it allows setting up a BIM project by defining characteristics of the site and of the building; DynamicData workbench allows generating Python objects usable as data containers for customizable properties; Defeaturing workbench is an add-on that allows editing features of imported NURBS models; Reporting workbench allows creating and managing custom queries based on SQL language. 
5.1.2 Material database: The second group of changes is referred to material database inside FreeCAD, that it has been implemented, through the material editor, with appropriate materials concerning the refectory, because the default database is design for AEC industry and are not suitable for historical architecture.

5.1.3 Roles and IFC entities classification: The last group is related to the modification of roles and classification for IFC entities, especially since FreeCAD, as other BIM software, doesn't include predefined classification (entities and roles) related to historical buildings, because standard BIM classification is referred to IFC2X3 and IFC4.1 schemas, designed for AEC industry (Scianna et al., 2015; Diara et a., 2018; Beltramo et al., 2019). Since BIM elements and surfaces have to be classified as architectural typologies (Macher et al., 2017), by using FreeCAD and its libraries this classification can be extended and modified including entities related to building archaeology, even if this customization is referred to the local system and fully operative within FreeCAD environment (Fig.8).

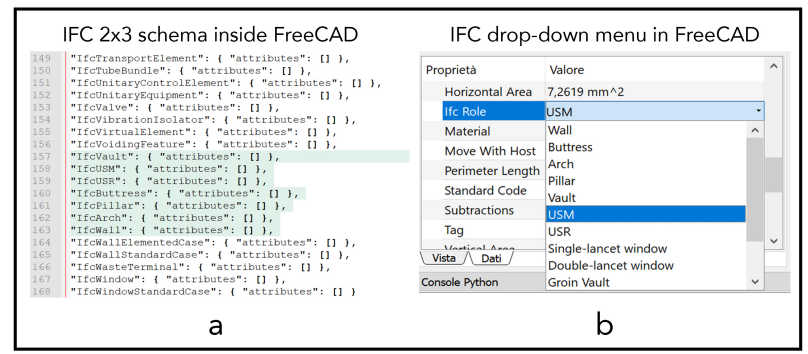

Figure 8. IFC entities implementation inside FreeCAD: from the customized schema (a) to the usable new classification inside FreeCAD (b)

Indeed, by using FreeCAD the IFC roles modification has been performed customizing every python script file related to the entities: for instance, IFC roles of ifcWall entity have been implemented by adding USM - USR as custom roles and subtypes inside the ArchWall.py file according to stratigraphic classification; IFC roles concerning ifcRoof entity have been integrated with roles and sub-types as Vault - Rib Vault - Groin Vault. In this sense, the most important additions on FreeCAD for this project concerning the Staffarda refectory have been ifcUSM; ifcUSR; ifcVault; ifcButtress; ifcPillar; ifcArch (entities not present inside the default IFC schema of FreeCAD). After this modification of python script files custom roles and sub-types appear into the drop-down menu of FreeCAD (Fig.8) concerning IFC roles, and in this way can be applied to architectural elements as well as stratigraphic units. Then, this step has played a fundamental role inside this project, especially regarding the data e query management.

\subsection{NURBS parametrization}

The refectory NURBS model has been subsampled (depending on architectural elements) and exported by using STEP format (Standard for the Exchange of Product model data). Then, NURBS shapes and surfaces are objects unusable inside a BIM environment because they are without the editable volumetric and thickness parameters and for this reason needs to be managed manually in order to become parametric objects (Oreni et al., 2014; Banfi F., 2017; Diara et al., 2019).

This procedure has been managed by using different FreeCAD workbenches: Defeaturing workbench has been used in order to remove original features of NURBS objects obtaining optimized surfaces ready to be extruded; the default Part workbench has been adopted for the purpose of using the extrusion command tool for the resulted surfaces, obtaining in this way editable volumetric and thickness parameters; DynamicData workbench has been helpful for the creation of Python "containers" for managing and customizing features, properties and metric data in real time, also using the internal database. Regarding the vaulted system, it has been extruded by calculating approximatively the brick thickness (about $28-30 \mathrm{~cm}$ ), because at the moment of the metric survey the crawl space was off limits. Moreover, the thickness value of stratigraphic units' surfaces has been managed and set on about $5 \mathrm{~mm}$ maximum per units, obtaining an extruded solid for each unit.

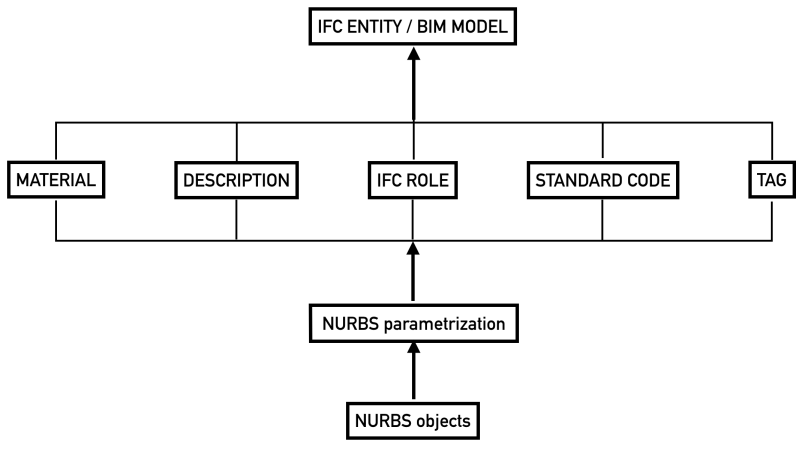

Figure 9. From NURBS objects to informative ones through specific properties and attributes inside FreeCAD

\subsection{Refectory HBIM platform}

5.3.1 IFC entity and roles attribution: The performed parametrization of NURBS surfaces allows to obtain parametric dynamic objects of architectural elements and stratigraphic units (Fig.10), ready to be classified as IFC entities for BIM purposes. Despite the standard IFC attribution of the ISO normative depending on IFC2X3 and IFC4.1 schemas and also depending on the implementation of these schemas on FreeCAD - for this project, as mentioned previously, has been designed customized and ad-hoc classification after the python script file integration related to entities.

So, the customized classification has been carried out for the purpose of including inside the HBIM projects particular historical elements, such as architectural elements and stratigraphic units. In this sense, it is referred to the inclusion of these custom IFC roles and sub-types: ifcUSM; ifcUSR; ifcVault; ifcButtress; ifcPillar; ifcArch. This customized classification occurred in FreeCAD, despite unusual and overlooking ISO standards, will become fundamental for the purpose of querying historical and metric data.

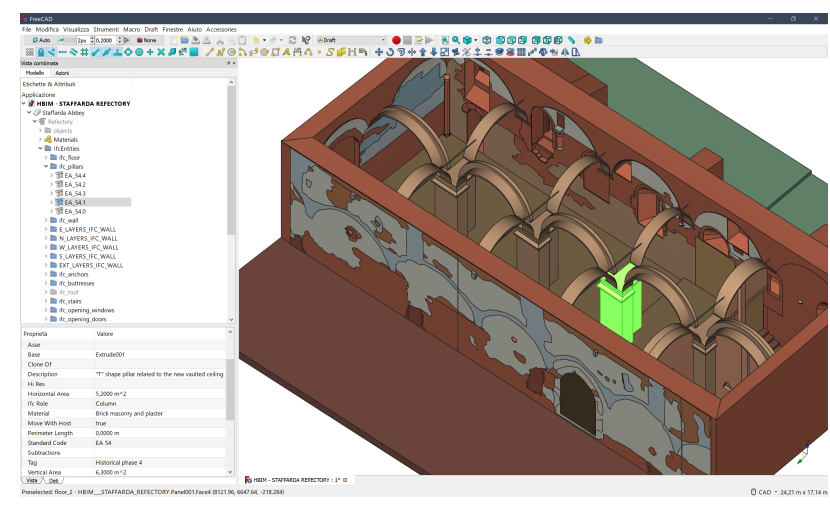

Figure 10. Refectory HBIM project: detail of the project tree and attributes on the left and the 3D space with the parametric model 
5.3.2 Description and information of entities: FreeCAD platform, apart from IFC classification, includes different parameters and attributes menu for IFC objects. Indeed, FreeCAD has a description voice fillable by using a text string: this space has been compiled with a brief text description of architectural elements and stratigraphic units; the material voice has been filled after the integration of the default material database with materials concerning the refectory (custom materials selectable from the new database); the standard code voice is referred to an optional identification code (text string) for objects and it has been used in order to integrate identification numbers of the stratigraphic units; tag voice permits to insert an optional text string tag for the object and it has been managed for the purpose of integrating the historical interpretation of the refectory (after the stratigraphic analysis) depending on historical phases and periods (Fig.11).

All these attributes and properties, as the IFC classification, will be deeply explored by managing custom querying operations, through the SQL query language.

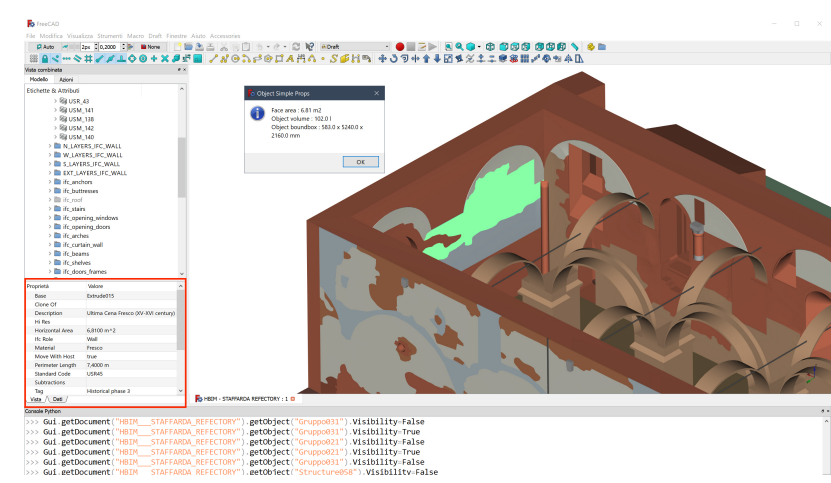

Figure 11. Refectory HBIM project: detail of USR45 with its attributes on the left and area and volume analysis

\section{DATA STORAGE AND QUERY}

Semantic and information dimension for HBIM purposes have to be planned in order to spread out the knowledge achieved and this is the principal reason why data shall be investigated through the utilization of internal databases, semantic relations as well as custom querying operations, establishing and allowing a sort of an on-demand comprehension and analysis depending on specific researches. Going deeper the integration of historical information is a mandatory step especially for documentation, management and monitoring operations, and, in this sense, data related to stratigraphic analysis has been fundamental inside this project.

\subsection{Semantic information}

The semantic dimension inside the HBIM platform has been set, depending on architectural classifications - material definitions - description - identification codes (related to stratigraphic analysis references numbers) - tags (related to historical interpretation based on chronological periods). In addition to these basic information concerning entities, FreeCAD allows, through the related properties menu, the implementation of other kinds of data and attributes, such as Addition, Hi-Res references as well as internal database custom implementation. Indeed, the Addition property field has been set including the picture of the related stratigraphic diagram (Matrix) with phases and periods for each stratigraphic unit (Fig.12), for the purpose of obtaining an immersive analysis on stratigraphy and the referred threedimensional parametric context.

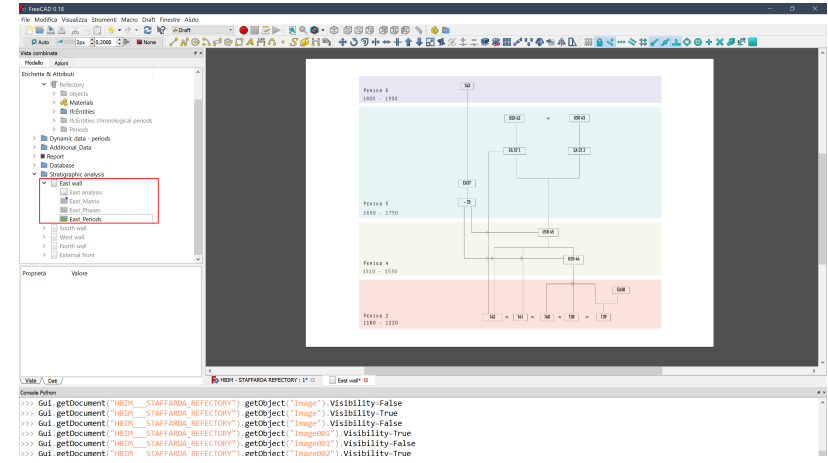

Figure 12. Inclusion of Matrix (Addition field) for each stratigraphic units' object: detail of east wall matrix with periods

Moreover, through the Hi-Res property field, detailed photographic references have been included for each stratigraphic unit as well as architectural elements (Fig.13). Regarding external references, inside the platform have been also included iconographic resources, historical pictures as well as bibliographic resources, in order to enrich the documentation value, allowing to carry out comparative analyses on the already performed historical interpretation and validate it.

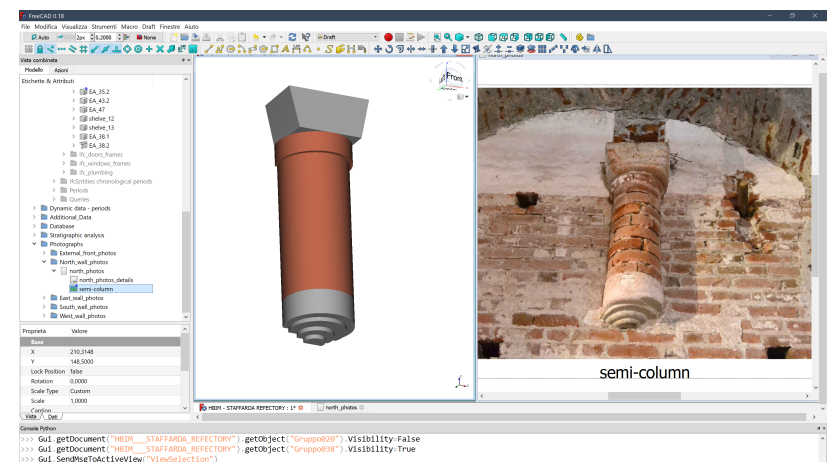

Figure 13. Inclusion of detailed photographs for each element and unit linked to Hi-Res property.

This semantic dimension, in addition to the fundamental stratigraphic analysis database inside FreeCAD - briefly composed by reference numbers of units, material reference and short description - exceeds limits of traditional building archaeology studies, overcoming data fragmentation by collecting a different kind of archaeological data inside a single dynamic platform that includes, as we have seen, different kind of data.

\subsection{SQL queries management}

The investigation phase for HBIM projects is a mandatory process in order to exploit the informative and semantic dimension, especially for deep specific analyses. For this project, these fundamental analyses have been performed by using SQL (Structured Query Language) open source query language inside the FreeCAD platform. SQL language has been implemented inside the platform through specific libraries, such as sqlparser in order to unlock and evocate the SQL language into a Python environment as FreeCAD. 


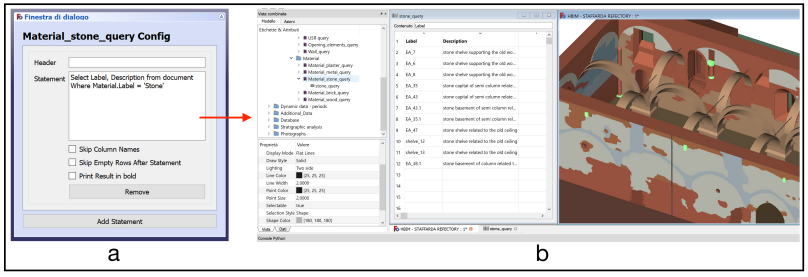

Figure 14. Reporting Workbench: SQL statement e precompiled custom query. Example of material stone element query.

Moreover, the additional Reporting Workbench has revealed fundamental for the purpose of managing SQL query operations, that can be carry out in two ways: first method relies essentially on FreeCAD Python console by writing SQL query as input and the console returns the result of the investigation as output (green text below the input); second method is based on SQL statement as input and a result / report as output, generating automatically a datasheet as output report, resulting more user friendly than the previous method (Fig.14). In this regard, last method could be the most suitable solution in order to pre-compile custom queries and share the results for example into an external database management system (Diara et al., 2018; Bruno et al., 2019).

\subsection{Querying the refectory}

The architectural elements as well as stratigraphic units of the refectory have been mostly investigated through the analysis of IFC entities, materials, standard codes (referred to reference number of stratigraphic units) and tags (related to chronological periods attribution).

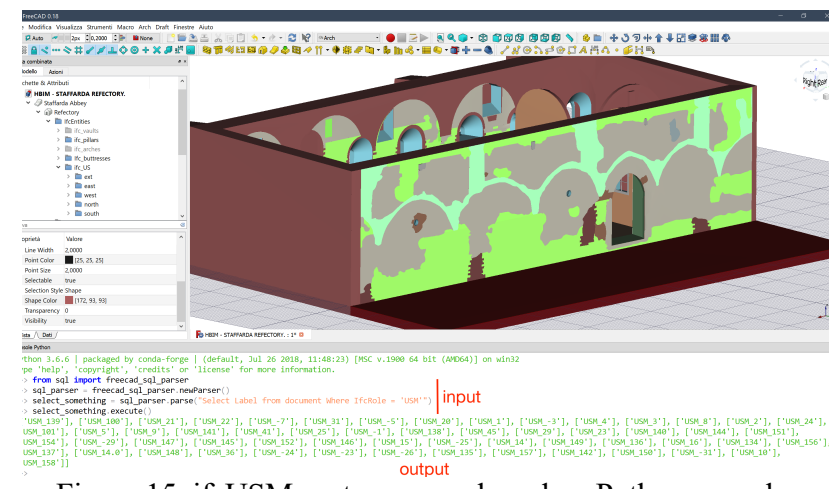

Figure 15. ifcUSM custom query based on Python console

Going deeper, IFC entities have been also interrogated testing the new custom classification referred to the implemented IFC schema inside FreeCAD, including, as we have seen, entities not designed for standard BIM projects such as ifcUSM - ifcUSR as sub-types of ifcWall; ifcVault as sub-type of ifcRoof; ifcPillar as sub-type of ifcColum (Fig.15-16).

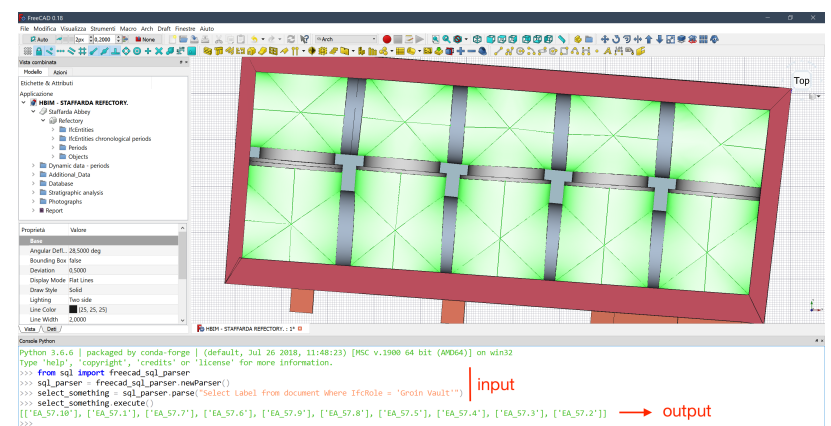

Figure 16. ifcGroinVault custom query based on Python console
Indeed, these custom entities and roles resulted available on the drop-down menu of properties and can be associated to specific objects and, acting in this way, Reporting Workbench through the SQL language can investigate them: in fact, SQL queries based on the SELECT syntax - performed by using Python console as well as SQL statement coupled with datasheet reports - can include the new custom classification without generating syntax or content errors (Fig.15-16-17).

In this way, custom queries can be carried out designed exclusively for archaeology as well as building archaeology purposes, creating an ad-hoc dynamic system based on particular historical information database and unconventional methods to collect, document and query it.

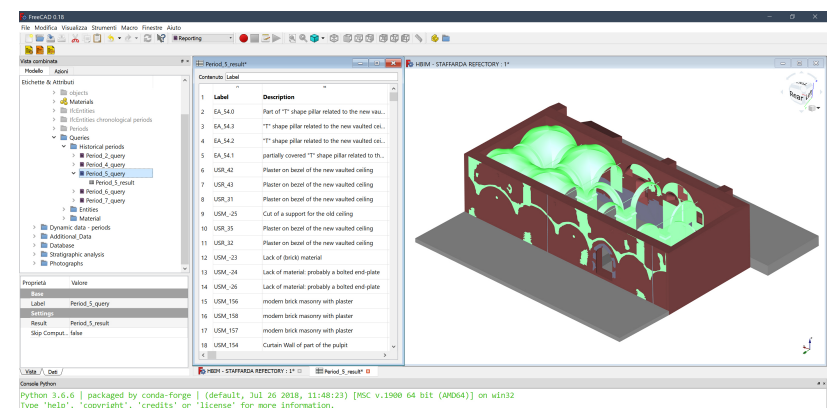

Figure 17. Chronological period 5 query through tags properties and based on SQL statement

\section{CONCLUSIONS}

The principal aim of this research was to take advantages and benefits of BIM methodology for buildings archaeology purposes through unconventional strategies, for example relying on FOSS solutions, especially since stratigraphic units as well as Cultural Heritage peculiarities have no BIM standard classification and BIM software support only workflow and project linked to AEC industry (Diara et al., 2018; Beltramo et al., 2019; Bruno et al., 2019).

Moreover, BIM software, both commercial and open source, have objective limitations concerning 3D modelling tools, based essentially on predefined architectural libraries that hardly fit with Cultural Heritage domain. This is the reason why this project relied on NURBS modelling by using Rhinoceros software, even if modelling the refectory by simplifying shapes and geometries. In this regard, FreeCAD acted well for the purpose of converting NURBS objects into parametric ones through additional libraries and workbenches.

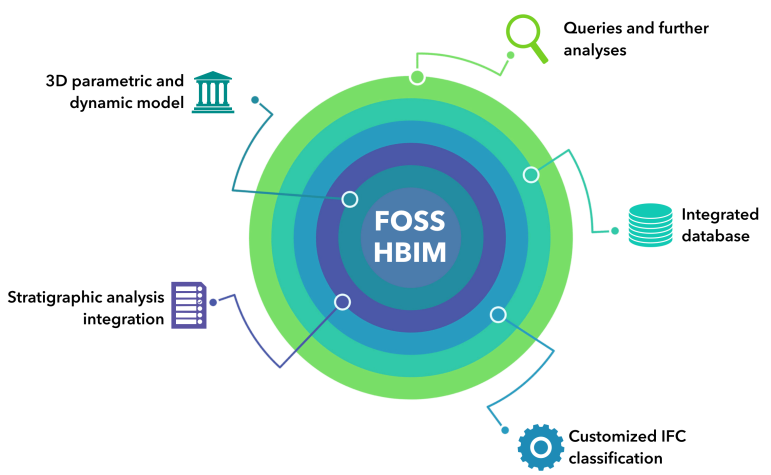

Figure 18. HBIM for building archaeology through open source and non-conventional solutions

Finally, analysing the obtained results we can argue that HBIM could be the proper methodology for building archaeology documentation and analysis, allowing to collect and share different kind of data, fundamental for deep analyses as well as 
conservation, restoration and monitoring operations (Beltramo et al., 2019; Bruno et al., 2019; Pocobelli et al., 2019; Trizio et a., 2019). Moreover, in this case FreeCAD - and its open source customizable code - has proved to be fundamental in order to overcome AEC limitations concerning IFC classification based on standard schemas, allowing custom analyses through ad-hoc queries, adapting software and methodology to specific research and not the opposite.

\section{ACKNOWLEDGMENTS}

This work was supported and funded by the GAMHer project (Geomatics data Acquisition and Management for landscape and built Heritage in a European perspective), a 3 years project financed under the Italian PRIN 2015 framework (Progetti di Ricerca di Rilevante Interesse Nazionale).

\section{REFERENCES}

Adami, A., Scala, B., and Spezzoni, A., 2017. Modelling and accuracy in a BIM environment for planned conservation: the apartment of Troia of Giulio Romano. In: The International Archives of the Photogrammetry, Remote Sensing and Spatial Information Sciences, XLII-2/W3, 17-23, 2017.

Banfi F., 2016. Building Information Modelling - A Novel Parametric Modeling Approach Based on 3D Surveys of Historic Architecture. Digital Heritage. Progress in Cultural Heritage: Documentation, Preservation, and Protection. pp.1-12. 2016

Banfi F., 2017. BIM orientation: grades of generation and information for different type of analysis and management process. In: The International Archives of the Photogrammetry, Remote Sensing and Spatial Information Sciences, XLII-2/W5, pp. $57-64$

Barazzetti, L., 2016. Parametric as-built model generation of complex shapes from point clouds. In: Advanced Engineering Informatics, 30 (2016) 298-311, 2016.

Beltramo, S., 2010. L'abbazia cistercense di Santa Maria di Staffarda. L'Artistica Editrice, Savigliano

Beltramo, S., 2016. Il romanico cistercense: analisi del costruito della chiesa e del monastero di Staffarda. In: Confronti vol. 10: Romanico piemontese - Europa romanica. Architetture, circolazione di uomini e idee, paesaggi. A cura di Saverio Lomartire. Centro Studi Città e Territorio. P.14-25

Beltramo, S., Diara, F., and Rinaudo, F., 2019. Evaluation of an integrative approach between HBIM and architecture history. In: The International Archives of the Photogrammetry, Remote Sensing and Spatial Information Sciences, XLII-2/W11, pp. 225229, 2019.

Brogiolo, G.P, Cagnana, A., 2012. Archeologia dell'architettura. Metodi e interpretazioni. Collana Metodi e temi dell'archeologia medioevale, Firenze: All'insegna del Giglio.

Bruno, N., Roncella, R., 2019. HBIM for Conservation: A New Proposal for Information Modeling. Remote Sensing, 2019, 11, 1751.

Diara, F., Rinaudo, F., 2018. Open source HBIM for Cultural Heritage: a project proposal. In: The International Archives of the Photogrammetry, Remote Sensing and Spatial Information Sciences, Vol. XLII-2, 2018 ISPRS TC II, pp. 303-309, 2018.
Diara, F., Rinaudo, F., 2019. From reality to parametric models of Cultural Heritage assets for HBIM. In: The International Archives of the Photogrammetry, Remote Sensing and Spatial Information Sciences, Vol. XLII-2, 2019, pp. 413-419, 2019.

Doglioni, F., 1988. La Ricerca sulle strutture edilizie tra archeologia stratigrafica e restauro architettonico, in $\mathrm{R}$. Francovich - R. Parenti (a cura di), "Archeologia e Restauro dei monumenti”, (Pontignano 1987), Firenze, All'Insegna del Giglio, 1988

Giannattasio, C., Papa, L. M., and D'Agostino, P., 2019. BIMoriented algorithmic reconstruction of building components for existing Heritage, Int. Arch. Photogramm. Remote Sens. Spatial Inf. Sci., XLII-2/W15, 513-518.

Harris, E., C., 2002. Principi di stratigrafia archeologia. Carocci editore, Roma.

ISO/TC 184/SC 4. (1994). "Industrial automation systems and integration - Product data representation and exchange-Part 11: Description methods: The EXPRESS language reference manual." ISO 10303-11:1994, Geneva.

Logothetis, S., Karachaliou, E., Stylianidis, E., 2017. From OSS $\mathrm{CAD}$ to BIM for Cultural Heritage digital representation. In: The International Archives of the Photogrammetry, Remote Sensing and Spatial Information Sciences. Vol. XLII- 2/W3, 2017.

Macher, H., Landes, T., Grussenmeyer, P., 2017. From Point Clouds to Building Information Models: 3D Semi-Automatic Reconstruction of Indoors of Existing Buildings. In: Applied Sciences 2017, 7, 1030.

Murphy, M., McGovern, E., Pavia, S., 2009. Historic building information modelling (HBIM). Structural Survey 27 (4), 311327.

Murphy, M., McGovern, E., Pavia, S., 2013. Historic Building Information Modelling - Adding intelligence to laser and image based surveys of European classical architecture. ISPRS Journal of Photogrammetry and Remote Sensing, 76, 89-102.

Oreni, D., Brumana, R., Banfi, F., Bertola, L., Barazzetti, L., Cuca, B., Previtali, M., Roncoroni, F., 2014. Beyond Crude 3D Models: From Point Clouds to Historical Building Information Modeling via NURBS. Lecture Notes in Computer Science. 8740. pp.166-175.

Parenti, R., 2000. Archeologia dell'Architettura. In R. Francovich \& D. Manacorda, (Eds.). Dizionario di archeologia. Temi, concetti, metodi (pp. 39- 43). Rome-Bari: Laterza

Pocobelli, D. P., Boehm, J., Bryan, P., Still, J., and Grau-Bové, J., 2018. Building information models for monitoring and simulation data in Heritage buildings, Int. Arch. Photogramm. Remote Sens. Spatial Inf. Sci., XLII-2, 909-916.

Scianna, A., Serlorenzi, M., Gristina, S., Filippi, M., Paliaga, S., 2015. Sperimentazione di tecniche BIM sull'archeologia romana: il caso delle strutture rinvenute all'interno della cripta della chiesa dei SS. Sergio e Bacco in Roma. In: Archeologia e calcolatori supplemento 7, pp. 199-212

Trizio, I., Savini, F., Giannangeli, A., Boccabella, R., and Petrucci, G., 2019. The archaeological analysis of masonry for the restoration project in HBIM, Int. Arch. Photogramm. Remote Sens. Spatial Inf. Sci., XLII-2/W9, 715-722. 